\title{
Pułapki (nie)pamięci. Przedstawienia GULagu w kulturze XXI wieku: literatura, film i sztuka
}

\section{Nina Frieß, „Inwiefern ist das heute interessant?“ Erinnerungen an den stalinistischen Gulag im 21. Jahrhundert, Leipzig 2016.}

\begin{abstract}
Artwińska Anna, Pułapki (nie)pamięci. Przedstawienia GUŁagu w kulturze XXI wieku: literatura, film i sztuka (The Traps of [Lacking]Memory. Representations of the GULag in the $21^{\text {st }}$ Century Culture: Literature, Film, and Art). "Poznańskie Studia Slawistyczne" 19. Poznań 2020. Publishing House of the Poznań Society for the Advancement of the Arts and Sciences, Adam Mickiewicz University, pp. 381-389. ISSN 2084-3011.

The subject of the article is the review of the book "Inwiefern ist das heute inter-essant?" Erinnerungen an den stalinistischen Gulag im 21. Jahrhundert by the German literary scholar Nina Friess (2016), which is dealing with the contemporary Russian memory of the Gulag. The goal is to show how the author interprets and contextualizes memory practices in today's Russia and which texts are crucial for her as manifestations of these remembering strategies (and forgetting as well). Reading this book allows to form the thesis that the extreme experience of the Soviet camps is still a controversial issue in the Russian culture and that the memory of it is full of gaps and empty spaces, even though at the same time this subject increasinly finds its way into popular cultural (graphic novels and crime thrillers).
\end{abstract}

KEYwORDS: GULag; camp literature; memory of communism; Stalinism

O ile we współczesnych humanistycznych badaniach nad Zagładą zaobserwować można współistnienie wielu różnorodnych koncepcji metodologicznych i teoretycznych, dzięki którym możliwa jest artykulacja zmian, jakie zachodzą w sposobach przedstawiania katastrofy Shoah w literaturze i sztuce, o tyle refleksja teoretyczna nad dynamiką literatury GUŁagu wypada - nie tylko w porównaniu - dość blado. W pamięci europejskiej 
istnieje rzecz jasna świadomość kanonu tekstów opisujących doświadczenia sowieckich łagrów ${ }^{1}$, nie brakuje także studiów naukowych poświęconych strategiom upamiętniania GUŁagu czy jego miejsca na mapie innych doświadczeń ekstremalnych w XX wieku, dużo trudniej jest jednak znaleźć prace poświęcone kwestiom strice metodologicznym² ${ }^{2}$ W kontekście literatury i sztuki GUŁagu nie pisze się zbyt wiele ani o postpamięci (Marianne Hirsch), ani o drugim czy trzecim pokoleniu po katastrofie; także kwestie związane z traumą czy materialnymi formami upamiętniania ${ }^{3}$ pojawiają się raczej marginalnie. Ma to po części związek z tym, że GUŁag, inaczej niż Holocaust, nie stał się po roku 1989 kamieniem węgielnym nowej Europy, a jego rozpoznanie rodzajem przepustki do świata europejskiej wspólnoty (Judt, 2014) - badania nad łagrami nie są tym samym tak intensywne jak badania nad Zagładą. Po części sytuacja taka wynika również z faktu, że w kontekście GUŁagu nadal dominują pytania fundamentalne, dotyczące przykładowo możliwości porównywania doświadczeń łagrowych z Shoah czy oceny komunizmu i jego miejsca w europejskiej historii. Już choćby ze względu na ową specyfikę badań nad łagrami i wynikającą z niej lukę warto sięgnąć po studium niemieckiej slawistki Niny Frieß, dotyczące form i strategii pamiętania oraz funkcji GUŁagu w (nie tylko rosyjskiej) literaturze i sztuce XXI wieku.

\section{GULag: aktualizacje i infotainment}

Praca „Inwiefern ist das heute interessant?” Erinnerungen an den stalinistischen Gulag im 21. Jahrhundert, powstała na podstawie rozprawy doktorskiej obronionej w 2015 roku na Uniwersytecie w Poczdamie, stawia

${ }^{1} \mathrm{Z}$ polskich prac historycznoliterackich wymienić należy studia Tadeusza Sucharskiego poświęcone m.in. twórczości Beaty Obertyńskiej, Jerzego Gliksmana, Anatola Krakowieckiego i Gustawa Herlinga-Grudzińskiego (v. Sucharski, 2008; Toker, 2000).

${ }^{2}$ Próbę komparatywnego spojrzenia na literaturę GUŁagu znaleźć można w książce zbiorowej Narratives of Annihilation, Confinement, and Survival. Camp Literature in a Transnational Perspektive (Tippner, Artwińska, 2019).

${ }^{3} \mathrm{~W}$ analizowanej książce Nina Frieß zwraca uwagę na to, że do dzisiaj władza w Rosji nie postawiła żadnego centralnego monumentu poświęconego ofiarom represji stalinowskich (v. Frieß, 2016, 73). Niemniej w Rosji od lat osiemdziesiątych widoczne są oddolne, intensywne dążenia do tworzenia miejsc mających chronić pamięć GUŁagu (v. Bogumił, 2012). 
pytanie o to, na ile doświadczenie GUŁagu stanowi współcześnie składnik (nie tylko rosyjskiej) pamięci żywej, widocznej medialnie i aktualizowanej z pokolenia na pokolenie. Nacisk został przy tym położony na sposoby przedstawiania doświadczeń łagrów stalinowskich: poza obszarem zainteresowań autorki znajdują się zarówno wcześniejsze, jak i późniejsze, poststalinowskie systemy opresji. Ninę Frieß zajmuje z jednej strony rola „klasyków": Aleksandra Sołżenicyna, Warłama Szałamowa i Eugenii Ginzburg, w formowaniu pamięci o GUŁagu oraz współczesne odczytania i adaptacje ich utworów, z drugiej strony narracje nowe, takie jak m.in. autofikcjonalna opowieść Granica zapomnienia (rus. Predel zabvenija) urodzonego w 1981 roku Siergieja Lebedewa czy powieści graficzne - graphic novels Danciga Baldajewa ${ }^{4}$. Frieß analizuje także wizerunki GUŁagu w kulturze popularnej (m.in. serial telewizyjny Testament Lenina z 2007 roku i kryminały) oraz co wydaje mi się niezwykle ciekawym aspektem - zastanawia się nad wizualną pamięcią o GUŁagu, w szczególności nad rolą zdjęć i obrazów w utrwalaniu wiedzy i memoryzacji systemu obozów pracy przymusowej w ZSRR ${ }^{5}$. Ramę metodologiczną rozważań wyznacza teoria pamięci (m.in. Aleidy Assmann i Astrid Erll), zwłaszcza zaś koncepcja literatury jako medium pamięci zbiorowej danego społeczeństwa. Ponadto autorka poprzedza analizę tekstów i artefaktów wprowadzeniem historycznym, w którym streszcza historię powstania GUŁagu i szkicuje kamienie milowe dyskursu pamięciowego o tym zjawisku w ZSRR/Rosji.

Za największą zaletę książki Frieß uważam to, że autorce udało się bardzo dobrze wytłumaczyć i opisać, dlaczego współczesne upamiętniania GUŁagu - mimo iż przybierają bardzo zróżnicowane formy i wykorzystują różnorakie strategie - nie odgrywają większej roli w kształtowaniu praktyk pamiętania o stalinowskiej przemocy. Autorka stawia tezę, że teksty i artefakty XXI wieku przyczyniają się raczej do cyrkulowania i rozpowszechniania wiedzy o GUŁagu niż do jej utrwalania, gromadzenia i zapisywania. Tym samym nie spełniają one (czy może raczej większość

\footnotetext{
${ }^{4}$ Po polsku powieść Lebedewa ukazała się w 2018 roku w przekładzie Grzegorza Szymczaka. Na marginesie warto wspomnieć, że problem oddziaływania tragedii GUŁagu na późniejsze pokolenia podejmuje także Dmitrij Bykow w powieści Oprawdanije z 2001 roku (po polsku powieść ukazała się pod tytułem Uniewinnienie w 2015 roku w przekładzie Ewy Rojewskiej-Olejarczuk).

${ }^{5}$ Cf. roz. 4.3. Bilder des Gulags (Obrazy GUŁagu) w analizowanej pracy.
} 
z nich) podstawowej funkcji stawianej mediom pamięci - funkcji zapisywania i przechowywania (Speicherfunktion). Przyczyn takiego stanu rzeczy szukać należy w tym, że współczesne utwory nie są w żaden sposób kodyfikowane, różna jest także ich dostępność i dystrybucja. Wprawdzie można założyć, że docierają one do większej liczby osób niż teksty zaliczane do tzw. kultury wysokiej, jednak ich recepcja jest bardzo często krótkotrwała i płytka. Frieß zwraca uwagę na to, że w Rosji nie odbyła się jak dotąd żadna generalna debata dotycząca przeszłości: problem zbrodni stalinowskich nie jest wprawdzie tematem tabu, nie doczekał się on jednak odpowiednich rozwiązań na poziomie politycznym. Jest znamienne, że żaden ze współczesnych, analizowanych przez autorkę utworów czy artefaktów nie wywołał dotychczas stosownych reakcji ze strony władzy choć niemal każdy z nich miał i ma potencjał, by stać się początkiem poważnej, ogólnonarodowej debaty. Problematyką GUŁagu interesują się wprawdzie w Rosji bardzo różne grupy, nie wchodzą one jednak ze sobą w dialog, w związku z czym rosyjskie praktyki pamiętania kształtują się osobno i wielotorowo. Prowadzi to do sytuacji, w której stosunkowo duża i różnorodna oferta rynkowa na temat doświadczeń łagrowych nie przekłada się na pogłębione i dojrzałe praktyki pamiętania, nie wiedzie do decydujących zmian w obowiązującym dyskursie i nie wprowadza tak bardzo potrzebnych korekt. Dobrym przykładem jest tu opera Odin den, powstała na podstawie świadectwa Aleksandra Sołżenicyna Jeden dzień z życia Iwana Denisowicza $(1962)^{6}$ w 2009 roku w miejscowości Perm, w reżyserii Georgija Isaakjana. Mimo że została ona bardzo dobrze przyjęta zarówno przez zawodowych krytyków, jak i operową publiczność, nie udało jej się przekonać Rosjan do konieczności krytycznych zmagań z własną przeszłością. Postawione po jej premierze przez dziennikarza Wiktora Wysockiego pytanie: „Na ile to jest dzisiaj w ogóle interesujące”, które Frieß uczyniła częścią tytułu swojej książki, wymownie streszcza jakże symptomatyczne dla rosyjskiej kultury pamięci oscylowanie pomiędzy uwspółcześnianiem a negacją i zapominaniem.

Części z analizowanych przez siebie przykładów autorka przypisuje wręcz ambicje czysto rozrywkowe - o GUŁagu można wszak opowiadać

${ }^{6}$ Po polsku tekst ten ukazał się w roku 1989 w przekładzie Witolda Dąbrowskiego i Ireny Lewandowskiej. 
zarówno mrożące krew w żyłach historie kryminale, jak i historie miłosne. Równocześnie rozrywka niemal zawsze idzie tu w parze $\mathrm{z}$ impulsem edukacyjnym - tym samym wiele $\mathrm{z}$ owych przedstawień GUŁagu należałoby zakwalifikować do gatunku infotainment, którego głównym celem jest wykorzystanie poruszającej fabuły i napięcia dramatycznego do przekazywania informacji o wybranym wydarzeniu. Dzięki temu odbiorca jest równocześnie konfrontowany $\mathrm{z}$,interesującą” historią i wiedzą o sowieckim systemie przemocy.

\section{Między pamięcią lokalną a transnarodową}

Omawiana praca skupia się na tekstach, obrazach i artefaktach rosyjskich, bada jednak także produkcje zagraniczne oraz recepcję twórczości autorów rosyjskich poza krajem. Frieß słusznie zwraca uwagę, że współcześnie granice pomiędzy poszczególnymi kulturami pamięci są płynne i nieszczelne - prowadzi to do wzajemnego przenikania i oświetlania się sposobów reprezentacji i pamiętania, wpływa także na recepcję. Jako przykład zagranicznych produkcji poświęconych problematyce GUŁagu autorka omawia m.in. film Within the Whirlwind w reżyserii Marleen Gorris z 2009 roku, bazujący na kanonicznych wspomnieniach Eugenii Ginzburg Stroma ściana ${ }^{7}$. Produkcja ta nie odniosła wielkiego sukcesu, przy czym o ile większość recenzentów i filmoznawców z zachodniej Europy i USA krytykowała film za jego emocjonalizm, powierzchowną realizację tematu oraz nieprzekonujące przedstawienie dramatu życia w łagrze, o tyle w Rosji widzowie pozytywnie wypowiadali się właśnie o jego afektywnym oddziaływaniu, pozwalającym na identyfikację z tragicznym losem głównej bohaterki. Dla Frieß różnice w odbiorze Within the Whirlwind są przykładem tego, że recepcja każdorazowo kształtowana jest przez dyskurs wspólnoty, w której powstaje, i że współcześnie pamięci lokalne nieustannie się ze sobą ścierają. Sytuacja współistnienia różnych wersji pamięci nie zawsze musi jednak generować konflikty czy być przeszkodą w wypracowywaniu pamięci transnarodowej. Świadczy ona raczej o tym, że pamięć transnarodowa jest niemożliwa bez pamię-

\footnotetext{
${ }^{7}$ Wydanie polskie ukazało się w 1990 roku w przekładzie Andrzeja Mandaliana.
} 
ci narodowych, na które wpływ wywierają pomniejsi, lokalni aktorzy analizowany przez autorkę fenomen potwierdza tezę de Cesari i Rigney $(2014,26)$, iż

there is no necessary or linear ,progress" from the familial, to local, to national, to global memory [...]. Indeed, the term transnational itself crucially serves here as a reminder of the fact that even in a so-called post-national age ,the national” as a framework $[\ldots]$ is still a powerful one.

Intensywne debaty, które w kulturze niemieckiej wywołała wspomniana wcześniej powieść Lebedewa - dopiero dzięki nim książką zainteresowano się w Rosji - potwierdzają według Frieß tezę o dużym znaczeniu warunkowanych lokalnie praktyk pamiętania. I tak zainteresowanie, jakie w Niemczech wywołała opowiedziana przez Lebedewa historia młodego człowieka, który nagle odkrywa, że jego tzw. „drugi dziadek” był komendantem w łagrze, łączyć należy z niemiecką historią i niemieckim doświadczeniem w przepracowywaniu traumatycznej przeszłości, konkretnie historii sprawców, oddziałującej także na późniejsze pokolenia.

W kontekście tych rozważań trochę szkoda, że badaczka nie uwzględniła w swoich analizach literatury czy filmów pochodzących z krajów Europy Środkowo-Wschodniej, skupiając swoją uwagę w pierwszej linii na różnicach między „Wschodem” a „Zachodem”. Wydaje się, że takie porównanie (na przykład między polską a rosyjską lub czeską a rosyjską pamięcią) byłoby poznawczo niezwykle ciekawe, choć gwoli sprawiedliwości trzeba dodać, że znalezienie współczesnych tekstów i artefaktów poświęconych problematyce GUŁagu i pochodzących z Europy Środkowo-Wschodniej byłoby z pewnością dość trudne (choć nie niemożliwe). Zamiast tego czytelnicy otrzymują omówienie innego, równie ciekawego fenomenu: anglo- i rosyjskojęzycznych kryminałów, których fabuła rozgrywa się w czasach stalinowskich i których akcja dzieje się częściowo na terenie łagrów. Gatunek ten, w pracy omawiany pod hasłem wywoławczym „From Russia with blood”, oferuje w pierwszej linii rozrywkę, jednak na metapoziomie konfrontuje już z pytaniami natury etycznej: czy stosowna jest fikcjonalizacja doświadczeń łagrowych, czy i na ile sowiecki system represji stanowić może kanwę opowieści zorganizowanej według gatunkowego klucza kryminału. Z analiz Frieß wynika, że tzw. new Soviet crimes novels (teksty Wiliama Ryana, Sama Eastlanda i Toma 
Roba Smitha, zwłaszcza zaś powstały w 2008 roku bestseller Child 44 tego ostatniego) z jednej strony przełamują historyczne tabu, opowiadając przykładowo o głodzie na Ukrainie w 1932-1933 roku czy analizując szczegółowo sowiecki system przemocy, z drugiej strony dokonują pewnych uproszczeń przeszłości, częściowo podyktowanych regułami gatunku. W kryminałach tych morderstwa dokonywane są w zamkniętym systemie obozu, na terenie otoczonym kolczastym drutem (autorka pisze o fenomenie tzw. zagadki zamkniętego pokoju - locked room mistery), zaś prowadzący śledztwo detektywi, nierzadko funkcjonariusze stalinowskiego systemu, unaoczniają fenomen przenikania się roli sprawcy i ofiary w kontekście doświadczeń ekstremalnych. Autorka dowodzi, że analizowane kryminały, choć spotkały się z szeroką recepcją w Rosji premiera filmu powstałego na kanwie bestselleru Smitha została początkowo przez władzę zablokowana - i wywołały falę rosyjskojęzycznych kontynuacji, traktowane być muszą jedynie jako przykład współczesnych aktualizacji tematyki GUŁagu, a nie teksty pamięciotwórcze. Toczone w kulturze rosyjskiej debaty wokół kryminałów, w szczególności tych anglojęzycznych, pokazują, że „w społeczeństwie rosyjskim trudno znaleźć konsensus odnośnie [adekwatnej] reprezentacji czasów stalinowskich", zaś „silna konkurencja pamięci uniemożliwia neutralną dyskusję na ten temat" (Frieß , 2016, 355 [przeł. - A.A.]). Mówimy tu o społeczeństwie, w którym niemal w każdej rodzinie znajdują się ofiary stalinowskiego systemu represji.

Książka „Inwiefern ist das heute interessant?” Erinnerungen an den stalinistischen Gulag im 21. Jahrhundert Niny Frieß uzupełnia studia niemieckich slawistów poświęcone problematyce GUŁagu. Warto w tym miejscu przypomnieć, że w roku 2009 ukazała się monografia Karoline Thaidigsmann dotycząca twórczości Warłama Szałamowa, Lwa Konsona, Nauma Nima i Andrieja Siniawskiego, zaś w roku 2012 Alfred Gall opublikował pracę poświęconą polskiej literaturze łagrowej w perspektywie komparatystycznej. W przeciwieństwie do swoich poprzedników Frieß w mniejszym stopniu interesują kwestie estetyczne, dotyczące możliwości narracyjnego uchwycenia i przekazania ekstremalnych doświadczeń: 
ambicją tej książki jest analiza mechanizmów pamięci i uchwycenie dynamiki rosyjskiego (nie)pamiętania GUŁagu. Z perspektywy polskiego czytelnika nie sposób przecenić jej wartość informacyjną: autorka bardzo szczegółowo omawia poszczególne utwory, każdorazowo pytając o ich rolę w kształtowaniu rosyjskich strategii przepracowywania traumatycznej przeszłości. Analizom Frieß brakuje czasami ukierunkowania literaturoznawczego, a więc refleksji nad strukturą retoryczną i stylistyczną analizowanych tekstów oraz nad możliwością przekładu teorii pamięci na języki artystyczne. Niemniej Frieß stawia istotne pytania o sposoby funkcjonowania pamięci kulturowej o GUŁagu w czasach globalizacji. Autorka pokazuje, że w procesach pamięciotwórczych każdorazowo dochodzi do faworyzowania nie tylko doświadczeń historycznych poszczególnych grup pamięci, ale również mediów i formatów. I tak współczesna pamięć GUŁagu jest bardziej określona przez obraz (filmy, seriale) czy formaty mieszane (opera) niż przez słowo, choć, paradoksalnie, jak pisze Frieß „na hasło «GUŁag» pamięć wizualna [Bildgedächtnis] większości ludzi, tak Rosjan, jak i nie-Rosjan, wskazuje na luki i puste miejsca" (Frieß, 2016, 127 [przeł. - A.A.]). Byłoby świetnie, gdyby analizowana tu książka stała się przyczynkiem do kolejnych badań dotyczących możliwości pamięci transnarodowej o GUŁagu oraz żeby w tych badaniach dalej pojawiały się pytania nie tylko o to, jak opowiadać o łagrach, ale także o oddziaływanie tych doświadczeń na naszą teraźniejszość.

\section{Literatura}

Bogumił, Z. (2012). Pamięć GUŁagu. Kraków: Universitas.

de Cesari, Ch., Rigney, A. (eds.) (2014). Transnational Memory: Circulation, Articulation, Scales. Berlin-New York: De Gruyter. https://doi.org/10.1515/9783110359107.

Frieß, N. (2016). Inwiefern ist das heute interessant? " Erinnerungen an den stalinistischen Gulag im 21. Jahrhundert. Leipzig 2016: Frank \& Timme. https://doi.org/ $10.3726 / \mathrm{b} 11787$.

Gall, A. (2012). Schreiben und Extremerfahrung - die polnische Gulag-Literatur in komparatistischer Perspektive. Berlin: Lit Verlag.

Judt, T. (2014). Powojnie. Historia Europy od roku 1945. Przeł. R. Bartołd. Poznań: Dom Wydawniczy Rebis.

Sucharski, T. (2008). Polskie poszukiwania ,innej Rosji”. O nurcie rosyjskim w literaturze Drugiej Emigracji. Gdańsk: Słowo/obraz terytoria. 
Thaidigsmann, K. (2009). Lagererfahrung und Identität. Literarische Spiegelungen sowjetischer Lagerhaft in Texten von Varlam Šalamov, Lev Konson, Naum Nim und Andrej Sinjavskij. Heidelberg: Universitätsverlag Winter.

Tippner, A., Artwińska, A. (eds.) (2019). Narratives of Annihilation, Confinement, and Survival. Camp Literature in a Transnational Perspektive. Berlin: De Gruyter. https://doi.org/10.1515/9783110631135.

Toker, L. (2000). Return from the Archipelago. Narratives of Gulag Survivors. Bloomington-Indianapolis: Indiana University Press. 